\title{
Analysis of Bimatoprost-Induced changes on Rabbits eyelash Follicle: Clinical and Electron microscopic study
}

This article was published in the following Dove Press journal: Clinical Ophthalmology

\author{
Khulood Muhammad Sayed' \\ Engy Mohammed Mostafa $\mathbb{D}^{\prime}$ \\ Amr Mounir (iD) \\ Nesreen G Abd Elhaliem² \\ Alahmady Hamad Alsmman (D) ' \\ 'The Department of Ophthalmology, \\ Sohag Faculty of Medicine, Sohag \\ University, Sohag, Egypt; ${ }^{2}$ The \\ Department of Histology, Sohag Faculty \\ of Medicine, Sohag University, Sohag, \\ Egypt
}

\begin{abstract}
Objective: To analyze ultrastructural changes of rabbits' eyelash follicles treated with bimatoprost eye drops to increase our knowledge of how this drug works.

Methods: The study included 15 clinically healthy male rabbits. All rabbits were treated with bimatoprost $0.03 \%$ daily for 4 weeks with one drop of the topical eye drops applied to the conjunctival fornix of the right eyes; left eyes were used as controls. Eyelash lengths were measured before and after treatment. The eyelid of each animal was dissected for light and electron microscopic analysis.
\end{abstract}

Results: Both control and treated rabbit eyes matched regarding eyelash length before treatment $(9.80 \pm 0.388 \mathrm{~mm}$ vs $9.88 \pm 0.24 \mathrm{~mm})(\mathrm{P}=0.108)$. There was a significant increase in eyelash length between control $(9.75 \pm 0.33 \mathrm{~mm})$ and treated rabbit eyes $(11.60 \pm 0.46 \mathrm{~mm})(\mathrm{P}=0.369)$. Light and electron microscopy revealed, bimatoprost treated eyes had thick epidermis. The dermis contained two hairs growing out of the same hair follicle. Heavily keratinized Henle's layer, the cortical cells $(\mathrm{Cx})$ have prominent nucleolus and cytoplasm is studded with melanin granules.

Conclusion: Bimatoprost-induced eyelash changes were not restricted to increased eyelash length, thickness, and pigmentation but also showed increased number of eyelashes within the same hair follicle which were stronger and could resist pulling from the skin without any evidence of inflammatory cells within the specimens. These changes occurred as early as 1 month of treatment, giving rise to thoughts about the possibility of using bimatoprost eye drops as a prophylaxis against madarosis associated with chemotherapy if it is started 1 month before chemotherapy and continued afterwards, making eyelashes stronger and resistant to falling out. Keywords: bimatoprost, rabbit, eyelash, hair follicle

\section{Introduction}

Prostaglandin F2 $\alpha$ analogs are very effective antiglaucoma drugs in modern glaucoma management. Bimatoprost is a synthetic prostamide which is structurally similar to other prostaglandin analogs, including latanoprost, travoprost, and unoprostone. ${ }^{1}$ Several side effects were reported with this group of eye drops including conjunctival hyperemia, increase of iris pigmentation, eyelid pigmentation, and periocular pigmentation. ${ }^{2}$ Yet the ability of this category of glaucoma medications to affect the growth of eyelashes has been widely noticed and reported in the literature. ${ }^{3,4}$ Prostaglandins are probably involved in a complex network in control of hair growth and differentiation. Most of the hair cell types are influenced with prostaglandin metabolism and all prostaglandin receptors are present in hair
Correspondence: Alahmady Hamad Alsmman

The Department of Ophthalmology, Sohag Faculty of Medicine, Sohag

University, Sohag 82524, Egypt

Tel +20 I I I I I02698

Email alahmady20@yahoo.com 
follicles. $^{5-7}$ In comparing bimatoprost to latanoprost in clinical studies, ophthalmic bimatoprost $0.03 \%$ was found to have a higher occurrence of eyelash growth. ${ }^{8-10}$ To the best of our knowledge, electron microscopic changes of the hair follicle after being exposed to bimatoprost in rabbits eye have not been evaluated before.

The purpose of this study was to report the histological and electron microscopic changes of hair follicles exposed to bimatoprost in rabbits eye in order to increase our knowledge of the way this medication works on eyelashes.

\section{Materials and Methods}

\section{Animals}

This study was carried out using 15 clinically healthy male rabbits, 6 months old, weighing 1.5 to $2.6 \mathrm{~kg}$. The animals in our study were selected randomly from a commercial breeder collection. Physical examinations were done before ocular examinations to exclude animals with any liability for systemic diseases.

All procedures using live rabbits were conducted according to guidelines for animal experimentation of the Institutional Animal Care. The ethics committee of the faculty of Medicine, Sohag University, officially approved the study.

Physical and ocular examinations were performed. Rabbits with any evidence of ocular or systemic diseases were excluded from the study. The same ophthalmologist (AH) instilled the eye drops and performed all the ocular tests.

\section{Treatment with Bimatoprost}

Bimatoprost belongs to a newer subset of PGs; prostamides which are created from anandamide that is derived from arachidonic acid. ${ }^{11,12}$ Anandamide is converted to prostamide $\mathrm{G} 2$ and $\mathrm{H} 2$ by cyclooxygenase (COX). Bimatoprost is a synthetic prostamide with a molecular formula of $\mathrm{C} 25 \mathrm{H} 37 \mathrm{NO} 4$. The unique substitution of ethyl amide instead of isopropyl ester at the C-1 carbon of the alpha chain gives different properties to bimatoprost than other PGF2 $\alpha$ analogs (latanoprost, travoprost, and unoprostone). ${ }^{13}$ All rabbits were treated with bimatoprost $0.03 \%$ (Lumigan; Allergan, Irvine, California, USA) daily for 4 weeks with one drop of the topical eye drops applied to the conjunctival fornix of animals' right eye. Left eyes were used as a control group with instillation of vehicle eye drops.

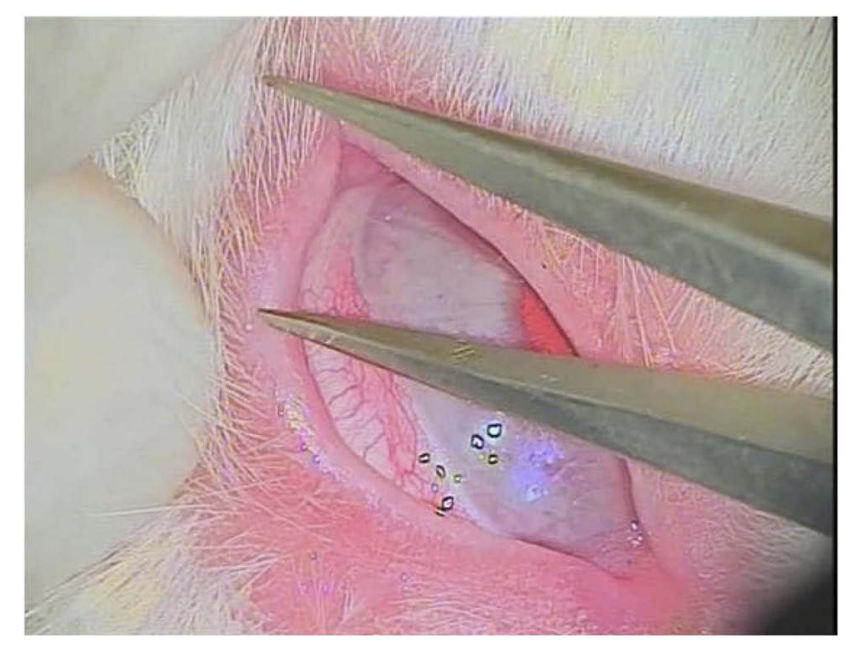

Figure I Measuring the eyelash of a rabbit using a caliber under microscope illumination.

\section{Measuring of Eyelash Length}

Eyelash lengths of both eyes were measured using a caliper one day before starting eye drops application. The selected measured eyelashes were the upper lid central top 5 eyelash lengths which were measured before and after treatment (at 30th day) (Figure 1). Measurement of each lash started from the end of the cilia to the base of the eyelid margin using the manual caliber.

\section{Histological Study}

After the end of the treatment, scarification was done. The eyelid of each animal in each group was dissected $24 \mathrm{hrs}$ after the last treatment dose, washed with saline, and divided into small pieces and immersed in $10 \%$ formalin for light microscopy and in $2.5 \%$ glutaraldehyde for transmission electron microscopy. The formalin fixed specimens were processed for preparation of serial paraffin sections of $5 \mu \mathrm{m}$ thickness for H\&E staining. ${ }^{14}$ The glutaraldehyde fixed ones were subjected to many steps to obtain ultra-thin sections that were contrasted with uranyl acetate for $10 \mathrm{~min}$ and lead citrate for $5 \mathrm{~min}$, and examined and photographed using a JEOL JEM 1010 electron microscope (JEOL Ltd, Tokyo, Japan) in the Electron Microscope Research Laboratory of the Histology and Cell Biology Department, Faculty of Medicine, Sohag University (Egypt).

\section{Statistical Analysis}

Paired $t$-test (SPSS) was performed for comparison of eyelash length between the eyes receiving bimatoprost and control group and to compare eyelash length before 
and after eye drops instillation. A P-value of $<0.05$ was considered statistically significant.

\section{Results}

\section{Eyelash Length}

Mean pre-treatment eyelash length value was 9.80 $\pm 0.388 \mathrm{~mm}$ versus $9.88 \pm 0.24 \mathrm{~mm}$ for control group with no significant difference between them $(\mathrm{P}=0.108)$ indicating that the groups were homogeneous before treatment. One month following bimatoprost eye drops application, treated group demonstrated a significant increase in mean eyelash length value $(11.60 \pm 0.46 \mathrm{~mm})$ when compared to control eyes $(9.75 \pm 0.33 \mathrm{~mm})$ or pre-treatment values $(\mathrm{P}=0.000)$. On the other hand, control group achieved no significant difference between pre $(9.80 \pm 0.388 \mathrm{~mm})$ and 1 month post vehicle application $(9.75 \pm 0.33 \mathrm{~mm})(\mathrm{P}=0.369)$, Table 1.

One month following treatment, there was a significant increase in thickness of the epidermis $(0.23 \pm 0.050$ vs 0.10 $\pm 0.033 \mathrm{P}=0.000$ ), number of hair shafts $/ 5$ hair follicles ( $7.80 \pm 1.82$ vs $4.40 \pm 0.82 \mathrm{P}=0.000)$, and ratio of anagen/telogen $(1.71 \pm 0.33$ vs $0.33 \pm 0.06, \mathrm{P}=0.000)$ for treated vs control eyes respectively, Table 1 .

\section{Histological Findings}

The upper eyelids of control rabbits were examined for the hair follicles of the eyelashes that were located at the free margin. They were penetrated deep from the thin epidermis into the dermis. Each follicle had a single hair shaft (Figure 2A).

The ultrastructure of the hair follicle of control eyelash of albino rabbit revealed that the outer root sheath (ORS) was surrounding the follicle from outside. The inner root sheath with its three layers was seen. Henle's layer had flat nuclei and the cytoplasm contained irregular shape trichohyalin granules, Huxley's layer was polygonal cells had oval nuclei with prominent nucleoli and distinct intercellular borders and cuticle single layer of thin flattened cells with no nuclei was also observed. The hair shaft cortex cells exhibited an irregular polygonal shape. They had distinct intercellular borders and were separated by cuticle from inner root sheath. The cytoplasm contained oval nuclei and cytoplasm contained numerous trichohylain granules and bundles of filaments while there were no melanin granules. The medulla cells appeared in the center of follicles detaching from each other (Figure 2B).

Bimatoprost treated group exhibited thick epidermis and most of the hair follicles of eyelash had more than one shaft in different stages of the hair cycle. Most of the hairs were in the anagen phase with apparent increase in the number of hair follicles. The dermal connective tissue contained dilated blood capillaries without inflammatory cellular infiltration (Figure 3A). The ultrastructure of the hair follicle of treated eyelash at level higher than suprabulpar area showed Henle's layer of inner root sheath with dense keratinized amorphous cells as trichohyalin granules accumulated and filled the cytoplasm with heterochromatic small nuclei. The electron dense cytoplasm of Huxley's layer cells was filled with variable sized irregular tricohyaline granules. The cortical cells of the hair shaft contained oval nuclei with prominent nuclei and cytoplasm was studded with variable sized smooth surface dense melanin granules (Figure 3B).

\section{Discussion}

There are a large number of clinical studies that investigated the effect of PGs analogs on hair growth either as a side effect $^{15,16}$ or in cases of hypotrichosis. ${ }^{4,17}$ The aim of the current study was to validate the microscopic effect of PGF $\alpha$ (bimatoprost) at level of hair follicles of rabbits' eyelids aiming for a better understanding of the mechanism of action of bimatoprost on eyelash follicles.

In this study we reported that topical bimatoprost once daily for one month showed thicker epidermis than in control eyes, indicating stimulation of skin cellular proliferation around the eyelash, this, together with the electron micrograph which showed heavily keratinized Henle's layer, indicate

Table I Comparison of the Histological Features Between Treated and Control Groups Before and After Treatment

\begin{tabular}{|l|l|l|l|l|l|l|}
\hline Mean & Treated Pre & Control Pre & P Value & Treated Post I m & Control Post I m & P Value \\
\hline Lash length in $\mathrm{mm}$ & $9.80 \pm 0.388$ & $9.88 \pm 0.24$ & 0.108 & $11.60 \pm 0.46$ & $9.75 \pm 0.33$ & $0.000^{*}$ \\
Thickness of epidermis in $\mu \mathrm{m}$ & $0.11 \pm 0.023$ & $0.095 \pm 0.046$ & 0.275 & $0.23 \pm 0.050$ & $0.10 \pm 0.033$ & $0.000^{*}$ \\
Number of hair shafts/5 hair follicles & $4.53 \pm 0.74$ & $4.60 \pm 0.83$ & 0.843 & $7.80 \pm 1.82$ & $4.40 \pm 0.82$ & $0.000^{*}$ \\
Ratio of anagen/telogen & $0.33 \pm 0.047$ & $0.34 \pm 0.064$ & 0.656 & $1.71 \pm 0.33207$ & $0.33 \pm 0.06$ & $0.000^{*}$ \\
\hline
\end{tabular}

Note: *Clinically significant $\mathrm{P}$ value. 

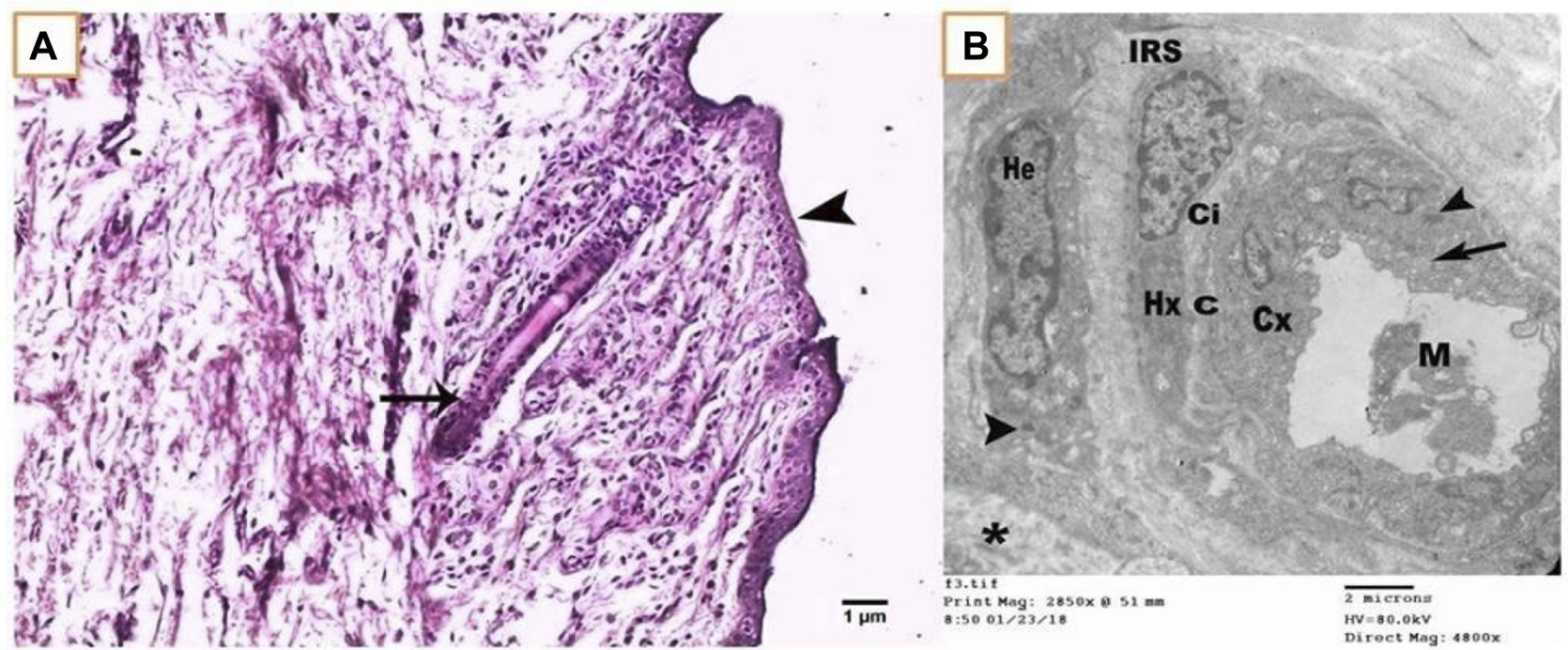

Figure 2 (A) Photomicrograph of control eyelid showing thin epidermis (arrowhead) and the dermis containing anagen hair follicle with its single shaft (arrow). Scale bar I $\mu \mathrm{m}$. (B) An electron micrograph of transverse section of hair follicle from control eyelash at suprabulbar level showing outer root sheath surrounding the follicle from outside $(*)$, the inner root sheath (IRS) with its three layers: Henle's (He), Huxley's (Hu), and cuticle (Ci). The hair shaft consists of cuticle (C), cortex cells (Cx), and medulla cells (M).

Note: Irregular shape trichohyalin granules (arrowhead) and bundles of filaments (arrow). Scale bar $2 \mu \mathrm{m}$.
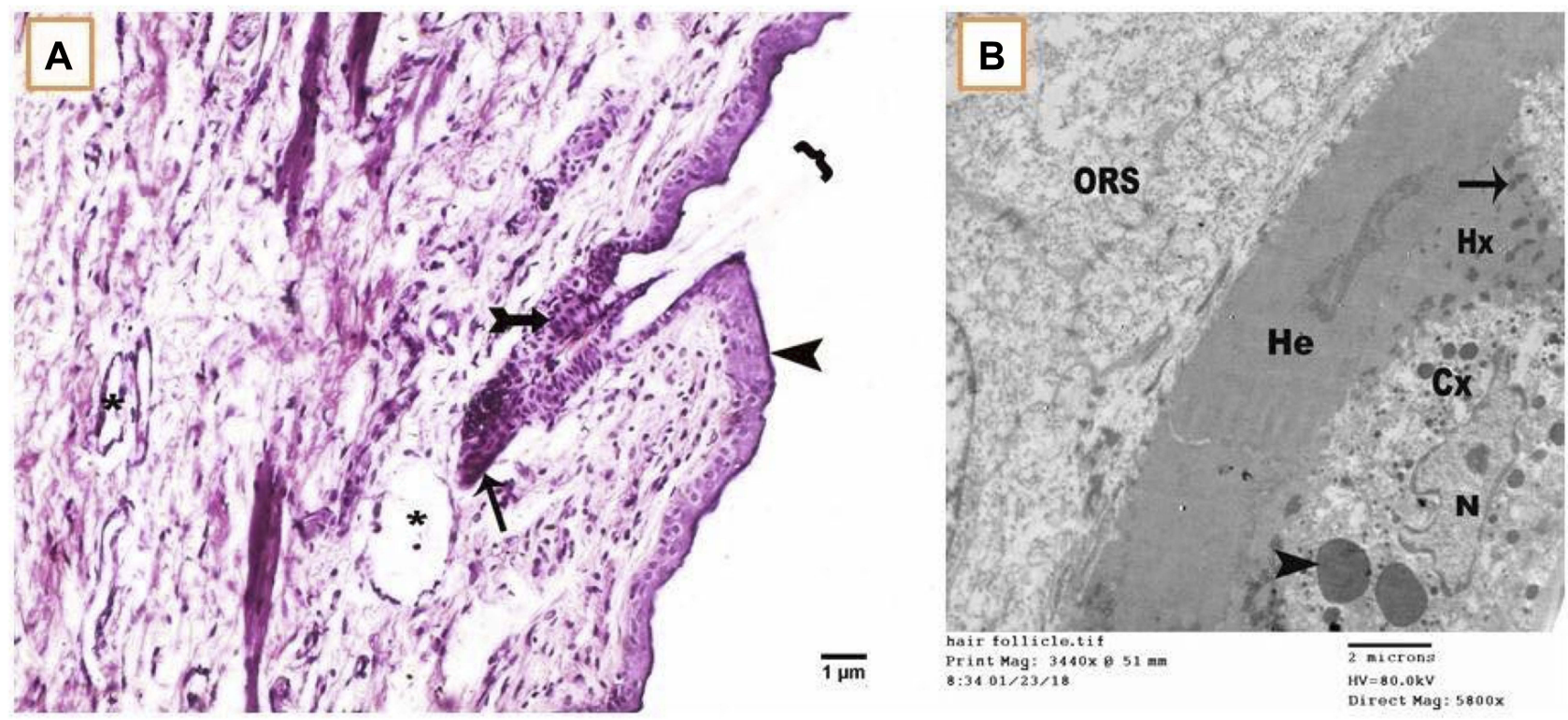

Figure 3 (A) Photomicrograph of treated eyelid showing thick epidermis (arrowhead) and the dermis containing two hairs growing out of the same hair follicle (\{). The bulb of telogen hair (tailed arrow) and the other of anagen (arrow) are shown.

Notes: Dilated blood vessels $(*)$. Scale bar I $\mu \mathrm{m}$. (B) An electron micrograph of transverse section of hair follicle from treated eyelid lash at higher than suprabulbar level showing heavily keratinized Henle's layer ( $\mathrm{He}$ ). The Huxley's layer cytoplasm contained irregular shape trichohyaline granules (arrow). The cortical cells (Cx) had oval nucleus (N) with prominent nucleolus and cytoplasm was studded with smooth surface dense granules of variable size (arrowhead). Scale bar $2 \mu \mathrm{m}$.

Abbreviation: ORS, outer root sheath.

changes of active process of keratinization making the eyelash stronger and resistant to pulling out of the skin. Other studies reported eyelid tightening and shortening in the NZW rabbit especially after 6 months of bimatoprost use. Periocular skin pigmentation was also observed previously with bimatoprost but occurred after several months of use. ${ }^{2,15}$

The effect of bimatoprost in making the eyelash stronger as early as 1 month of therapy may be beneficial in 
treating patients suffering from weak eyelashes with frequent falling of lashes from lid margin.

The dermis contained two hairs growing out of the same hair follicle; bulb of telogen hair and the other of anagen. It was reported previously that bimatoprost stimulates the prostamide receptor, leading to the transition of hair follicles from the telogen phase to the anagen phase. ${ }^{18}$ In this study, the combination of telogen and anagen phases of the hair cycle in the same follicle indicates that bimatoprost not only stimulates transition from telogen to anagen phase, it even stimulates a new hair cycle in the same follicle giving rise to more than one eyelash within the same follicle leading to increase in the number of eyelashes. Bimatoprost cannot increase the number of hair follicles as the number of follicles cannot be increased after birth because all follicles develop during embryogenesis. ${ }^{19}$

Stimulation of anagen phase (growth phase) by bimatoprost largely determines the length of eyelashes. ${ }^{20}$

Regarding blood vessels in the dermal papillae, they nourish all hair follicles and bring nutrients and oxygen to the lower layers of epidermal cells; the presence of dilated blood vessels of the hair follicles of the treated eyes is essential for the actively occurring cellular proliferation and differentiation of the stimulated anagen phase. ${ }^{20}$

Vasoactive properties of bimatoprost were also reported previously by Allemann et al. ${ }^{21}$

In addition; prostaglandins (PGs) were described in the literature as a promoter of neovascularization, especially the subtype $\mathrm{PGE}_{1}{ }^{22}$

And have also been reported to have an immense effect on relaxation of rabbit ciliary arteries. ${ }^{23}$ Thus they have a profound vasodilatory effect on the vessels of the dermis including the perifollicular blood vessels, as detected by electron microscopy.

Previous reports tried to highlight the effect of other medications on hair growth, in a study of Song et al, ${ }^{24}$ they reported a case of unexpected eyelash growth much longer than they were normally, under the effect of ruxolitinib treatment. Also, in a study of Riahi et $a l,{ }^{25}$ they reported excellent and sustained growth of eyebrows with continual daily use of bimatoprost $0.03 \%$ solution.

In this study, the electron micrograph of transverse section of hair follicle from treated eyelid lash showed that; the Huxley's layer cytoplasm contained irregular shape trichohyaline granules which indicate active process of keratinization. The cortical cells $(\mathrm{Cx})$ had oval nucleus $(\mathrm{N})$ with prominent nucleolus; all of these are features of active process of cellular proliferation and differentiation of anagen phase. The cytoplasm of the cortical cells was noted to be studded with melanin granules (the smooth surface dense granules).

Melanogenesis, and the subsequent transfer of pigment from melanocytes to cortical and medullary cells of the follicle, occurs only during anagen phase. ${ }^{26}$

There was increased thickness of hair together with increased pigmentation surrounding the follicle as well. Bimatoprost was reported to increase melanogenesis via stimulation of the enzyme tyrosinase causing darkening. ${ }^{27}$

The fact that hair follicles are able to produce $\mathrm{PGE}_{2}$ and $\mathrm{PGF}_{2 \alpha}$, and all of the PG receptors are present in the hair follicle, ${ }^{5-7}$ account for those effects of bimatoprost. The rapid action of bimatoprost is believed to be due to its composition as a prostamide that does not need to be converted to active metabolite to prolong its pharmacological activity. ${ }^{8}$

This paper sheds new light on the microscopic changes caused by topical bimatoprost, PG analog. It illustrates electron microscopic findings of hair follicles which, to the best of our knowledge, have not been evaluated before. Yet, future work should focus on how long the effect of bimatoprost will last after discontinuation of the drug and also determine the effect of drug in cases of madarosis with atrophied or destructed hair follicles as in cases of post-irradiation or chemical trauma, and also whether it has a protective effect against madarosis associated with chemotherapy or not.

\section{Disclosure}

The authors report no conflicts of interest in this work.

\section{References}

1. Cantor LB. Clinical pharmacology of bimatoprost. Expert Opin Drug Metab Toxicol. 2005;1(1):151-157. doi:10.1517/17425255.1.1.151

2. Hollo G. The side effects of the prostaglandin analogues. Expert Opin Drug Saf. 2007;6(1):45-52. doi:10.1517/14740338.6.1.45

3. Johnstone MA. Hypertrichosis and increased pigmentation of eyelashes and adjacent hair in the region of the ipsilateral eyelids of patients treated with unilateral topical latanoprost. Am J Ophthalmol. 1997;124(4):544-547. doi:10.1016/S0002-9394(14)70870-0

4. Law SK. Bimatoprost in the treatment of eyelash hypotrichosis. Clin Ophthalmol. 2010;4:349-358. doi:10.2147/OPTH

5. Colombe L, Vindrios A, Michelet JF, Bernard BA. Prostaglandin metabolism in human hair follicle. Exp Dermatol. 2007;16 (9):762-769. doi:10.1111/j.1600-0625.2007.00586.x

6. Colombe L, Michelet JF, Bernard BA. Prostanoid receptors in anagen human hair follicles. Exp Dermatol. 2008;17(1):63-72. doi:10.1111/ j.1600-0625.2007.00639.x

7. Torii E, Segi E, Sugimoto Y, et al. Expression of prostaglandin E(2) receptor subtypes in mouse hair follicles. Biochem Biophys Res Commun. 2002;290(2):696-700. doi:10.1006/bbrc.2001.6256

8. Gandolfi S, Simmons ST, Sturm R, et al. Three-month comparison of bimatoprost and latanoprost in patients with glaucoma and ocular hypertension. Adv Ther. 2001;18(3):110-121. doi:10.1007/BF02850 299 
9. Noecker RS, Dirks MS, Choplin NT, et al. A six-month randomized clinical trial comparing the intraocular pressure-lowering efficacy of bimatoprost and latanoprost in patients with ocular hypertension or glaucoma. Am J Ophthalmol. 2003;135(1):55-63. doi:10.1016/S00 02-9394(02)01827-5

10. Konstas AG, Katsimbris JM, Lallos N, et al. Latanoprost $0.005 \%$ versus bimatoprost $0.03 \%$ in primary open-angle glaucoma patients. Ophthalmology. 2005;112(2):262-266. doi:10.1016/j.ophtha.2004.08.022

11. Woodward DF, Krauss AH, Chen J, et al. The pharmacology of bimatoprost (Lumigan). Surv Ophthalmol. 2001;45(Suppl 4):S337S345. doi:10.1016/S0039-6257(01)00224-7

12. Woodward DF, Krauss AH, Chen J, et al. Pharmacological characterization of a novel antiglaucoma agent, bimatoprost (AGN 192024). $J$ Pharmacol Exp Ther. 2003;305(2):772-785. doi:10.1124/jpet.102. 047837

13. Woodward DF, Liang Y, Krauss AH. Prostamides (prostaglandin-ethanolamides) and their pharmacology. $\mathrm{Br} J$ Pharmacol. 20 08;153(3):410-419. doi:10.1038/sj.bjp.0707434

14. Bancroft JD, Gamble M. Theory and Practice of Histological Techniques. 6th ed. Philadelphia: Churchill Livingstone, Elsevier; 2008.

15. Alm A, Grierson I, Shields MB. Side effects associated with prostaglandin analog therapy. Surv Ophthalmol. 2008;53(Suppl1):S93S105. doi:10.1016/j.survophthal.2008.08.004

16. Moroi SE. Eyelash preservation during chemotherapy and topical prostaglandin therapy. Arch Intern Med. 2010;170(14):1269-1270. doi:10.1001/archinternmed.2010.247

17. Hart J, Shafranov G. Hypertrichosis of vellus hairs of the malar region after unilateral treatment with bimatoprost. Am J Ophthalmol. 2004;137 (4):756-757. doi:10.1016/S0002-9394(03)01075-4

18. Suwanchatchai W, Tanglertsampan C, Pengsalae N, Makornwattana M. Efficacy and safety of bimatoprost $0.03 \%$ versus minoxidil $3 \%$ in enhancement of eyebrows: a randomized, double-blind, split-face comparative study. J Dermatol. 2012;39 (10):865-866. doi:10.1111/jde.2012.39.issue-10
19. Habif TP. Hair diseases. In: Habif TP, editor. Clinical Dermatology: A Color Guide to Diagnosis and Treatment. 4th ed. St. Louis, MO: C. V. Mosby Company; 2003.

20. Randall VA. Hormonal regulation of hair follicles exhibits a biological paradox. Semin Cell Dev Biol. 2007;18(2):274-285. doi:10.1016/j.semcdb.2007.02.004

21. Allemann R, Flammer J, Haefliger IO. Vasoactive properties of bimatoprost in isolated porcine ciliary arteries. Klin Monbl Augenheilkd. 2003;220(3):161-164. doi:10.1055/s-2003-38167

22. Mehrabi MR, Serbecic N, Tamaddon F, et al. Clinical benefit of prostaglandin E1-treatment of patients with ischemic heart disease: stimulation of therapeutic angiogenesis in vital and infarcted myocardium. Biomed Pharmacother. 2003;57(3-4):173-178. doi:10.1016/S0753-3322(03)00026-X

23. Ishikawa H, Yoshitomi T, Mashimo K, et al. Pharmacological effects of latanoprost, prostaglandin E2, and F2alpha on isolated rabbit ciliary artery. Graefes Arch Clin Exp Ophthalmol. 2002;240 (2):120-125. doi:10.1007/s00417-001-0412-4

24. Song J, Song A, Palmares T, Song M, Song H. Ruxolitinib found to cause eyelash growth: a case report. J Med Case Rep. 2017;11 (1):189.1304-5. doi:10.1186/s13256-017-1304-5

25. Riahi RR, Cohen PR. Topical treatment of eyebrow hypotrichosis with bimatoprost $0.03 \%$ solution: case report and literature review. Cureus. 2018;10(5).

26. Johnstone MA, Albert DM. Prostaglandin-induced hair growth. Surv Ophthalmol. 2002;47(Suppl 1):S185-S202. doi:10.1016/S0039-6257 (02)00307-7

27. Cohen JL. Enhancing the growth of natural eyelashes: the mechanism of bimatoprost-induced eyelash growth. Dermatol Surg. 2010;36 (9):1361-1371. doi:10.1111/j.1524-4725.2010.01522.x
Clinical Ophthalmology

\section{Publish your work in this journal}

Clinical Ophthalmology is an international, peer-reviewed journal covering all subspecialties within ophthalmology. Key topics include: Optometry; Visual science; Pharmacology and drug therapy in eye diseases; Basic Sciences; Primary and Secondary eye care; Patient Safety and Quality of Care Improvements. This journal is indexed on PubMed

\section{Dovepress}

Central and CAS, and is the official journal of The Society of Clinical Ophthalmology (SCO). The manuscript management system is completely online and includes a very quick and fair peer-review system, which is all easy to use. Visit http://www.dovepress.com/ testimonials.php to read real quotes from published authors. 